\title{
Impact of Neuroscience in Middle School Science Education
}

\author{
Rosa Pereira \\ University of Nottingham, Nottingham, UK \\ Oporto International School-CLIP, Oporto, Portugal
}

\author{
Mariana Guerra, Raquel Loureiro \\ Oporto International School-CLIP, Oporto, Portugal
}

\begin{abstract}
Educational neuroscience, also known as brain-based learning, is a novel discipline for educators and has, to date, being visible only as an academic discussion focus. Different lookouts, influences, and thoughts are thus simply noticeable in reviews. In recent decades, researchers in educational neuroscience have been captivated by the manner the brain is able to process scientific critical thinking, an indispensable $21^{\text {st }}$ century competency. They tried to propose an explanatory model for how the brain processes critical thinking skills, necessary in science learning. Although these models are starting to clarify how the brain works, they failed so far to make a strong impact on the field of science education. This research offers an insight into the research, on the use of neuroscience to teach science to middle school students in a Portuguese International School. The study investigated the effect of educational neuroscience on academic outcome and retention of previously acquired knowledge, inside Science laboratory classrooms. The authors also explored the relationship between experimental learning and the enhancement of creative problem solving (higher-order cognitive) skills in the classroom. The results favored the neuroscience learning methodologies. Finally, it supports the application of neuroscience in the laboratory classroom, and aims to explain how the laboratory classroom should be prepared for a successful educational neuroscience approach.
\end{abstract}

Keywords: educational neuroscience, traditional teaching methods, science, middle-school teaching

\section{Introduction}

Cognitive neuroscientists have made a substantial effort to understand how the brain learns and adapts, and there has been considerable interest in translating this work into practice. It is not yet clear, however, how we should apply such findings to education in the classroom.

Teachers on other hand are "brain changers". As teachers, it seems evident that understanding the brain, the learning organ, is an important tool for an effective teaching practice. A "neuroteacher" can be defined as the one that is able to intentionally apply the research of neuroscience into their instructional design and individual work with the student (Whitman \& Kelleher, 2016). It is important to "bridge the gap" between neuroscience and the design of classrooms and individual work with students.

The brain is the organ of learning. As teachers, we need to understand how we can help students to meet his or her best potential and promote simultaneously a better understanding on their own as a learner. Students on other hand, need to comprehend that the most important tool they can bring to the classroom is their brain.

Rosa Pereira, Pharm D, Ph.D., Oporto International School-CLIP; School of Education, University of Nottingham. Mariana Guerra, BmedSc, M.B.A, Oporto International School-CLIP. Raquel Loureiro, BSc, M.Ed, Oporto International School-CLIP. 
Teachers quality underpins students' outcome. Efficient teachers believe they can transform the life of students. They want to feel professionally challenged and are updated in terms of educational research. Moreover, they are more efficient since they correlate students learning to an increase knowledge of the brain (Sousa, 2009). As such, they realize that the one-size-fits-all model of education is not an equitable educational experience for the $21^{\text {st }}$ century students.

Several scientists (Hardiman, Tokahama-Espinosa, Sousa, Tomlinson, Willingham just to name a few) have tried to bridge the gap between research and practice. Research revealed that educational neuroscience works for all students. Despite each student possessing an individual learning preference, research shows that they learn best when taught in a variety of modalities. These modalities are varied from concept to concept, being our personal view that teachers should differentiate based on content rather than in learning style. Teachers should align the brain demands with the material that they want to teach, how they want to teach it, and how to assess it. This will benefit students in their acquisition of a crucial set of school, future job, and life skills, commonly known as $21^{\text {st }}$ century competencies that are necessary for efficient science education (Wieman, 2008).

Nevertheless, there are still challenges ahead, when we tried to integrate educational neuroscience into pedagogical practices. This study tries to "bridge the gap" between the incorporation of educational neuroscience strategies recommended by Sousa and Tomlinson (2011); Hardiman (2012); Whitmann and Kalleher (2016) and the learning design of science in two middle school classrooms in a Portuguese Private International School.

\section{Purpose of the Study}

The goal of the study was to establish a comparison between students' attitudes and outcome gains using traditional (didactic) teaching method and educational neuroscience techniques in a middle-school international school Science course.

Two research questions guided the study:

(1) What differences exist in student satisfaction with the learning environments (traditional classrooms versus laboratory classrooms)? and

(2) What differences exist in outcome gains between students taught using traditional teaching methods and those taught using Educational neuroscience?

\section{Methodology}

The population for this study consisted of 42 students that were enrolled in a middle school science program in a Portuguese International School. There were 18 males, and 24 females $(N=42)$. Students were enrolled in two different forms at the beginning of the academic year. One of the forms was taught using traditional (lecture-based) methods while the other utilized educational neuroscience techniques. The course was run through a three-week period, with a total of three hours of teaching spread across each week.

A survey instrument was created to assess student satisfaction with the learning environment and subject. It included demographics of the student (gender, age, race, and whether presented any English Additional Language (EAL)), course objectives, and outcomes (five-point Likert-type scale from 1 = very unsatisfactory to 5 = very satisfactory), being the former reported in the current study. Moreover, students view towards the traditional teaching method and educational neuroscience (five-point Likert-type scale), and open-ended 
questions about course satisfaction, were also considered. Pre- and post-assessment data were compared to evaluate whether or not a change in attitude toward science had occurred during a change in the classroom learning environment (laboratory-based teaching).

The results showed that ten percent of the students did not like science whereas $89 \%$ like it. Sixty nine percent of the students considered science to be their favorite discipline. Post-assessment results indicated that students increased their engagement towards learning science more than at pre-assessment evaluation. Moreover, pre-assessment results showed that $30 \%$ of the students believe that they could learn science better from laboratory classroom activities, but post-assessment results showed an increment of up to $93 \%$ of the students choosing that category. Conversely, $27 \%$ of the students who chose to disagree during pre-assessment, change their opinion, being only $4 \%$ with the same idea. The results of the statistics (t-tests) for the fourth and fifth research questions revealed that the only difference at 0.05 level of significance was related to the feeling of being supported and safe. Students taught by the traditional method responded well to the practical lessons, but the neuroeducational approach resulted in a better feeling of being safe and supported in lessons taught by the neuroeducational method (Table 1).

Table 1

Statistical Comparisons of Students’ Answers

\begin{tabular}{lllll}
\hline \multirow{2}{*}{ Question } & \multicolumn{3}{c}{ Group means* } \\
\cline { 2 - 5 } & Neuroeducational & Traditional & $t$ & Sig. \\
\hline Q1 & 1.25 & 1.45 & 1.074 & 0.998 \\
Q2 & 4.00 & 4.09 & -1.948 & 0.438 \\
Q3 & 3.32 & -2.516 & 0.598 \\
Q4 & 4.00 & 4.00 & -3.737 & 0.054 \\
Q5 & 4.60 & 4.36 & -4.183 & $0.000^{* *}$ \\
\hline
\end{tabular}

Notes. * A 5-point Likert scale, where 1 indicated "strongly agree", 2 "agree", 3 indicated "unable to decide", 4 indicated “disagree", and 5 "strongly disagree”; ** denotes significant difference at .05 level. df (degrees of freedom) $=40$.

T-assessments for independent means were used to compare students' satisfaction of the learning environment between the two groups. A separate t-assessment for independent means was used to compare the mean score on each Likert-scaled item between the experimental and control groups. Student responses to open-ended (satisfaction of teaching method) were collected, but it was not reported in the current paper.

Since content differentiation was considered, the course syllabus outlined in detail what students should know (K), understand (U), and be able to do (D) at the end of the unit under study. In the lecture-based class, students were given worksheets and lectures that supported the know, understand, and be able to do (KUD(s)). Required written homework's needed to be submitted on specific dates and a final summative assessment was administered. The laboratory lessons were conducted according to pre-stablished experimental protocols and assessment questions were provided at the end of those. In the educational neuroscience approach, learning design was based on the work published by Sousa and Tomlinson (2011). Differentiation based on student readiness was considered, a detailed instruction plan was constructed based on content differentiation to support student readiness. Tiering was considered to warrant that each student was working at a level of moderate challenge. Moreover, students were given a basic understanding of neuroscience educational learning and what their responsibilities involved. 
The final grade for both control and treatment groups was based upon class attendance, completion of assignments, and assessment scores.

A pre-assessment was distributed before the start of the unit, to ensure an alignment between KUDs and the different tiers. Post-assessment was administered in the last class along with the student satisfaction assessment course survey. The pre-assessments and post-assessments were administered by the teacher. Students had ample time (30-60 minutes) to complete their assessments.

This study utilized both qualitative and quantitative research methods. Cross and Steadman (1996) stated that educators were provided with tools that enabled them to engage their students by converting their classrooms in laboratories to conduct an improvement on student education.

The quantitative research method utilized was a quasi-experimental design. The nonequivalent control-group design, used intact groups where the teacher and students were not randomly selected and assigned to the experimental and control groups. The design involved the administration of a pre-assessment and post-assessment to both the experimental and control groups.

Analysis of variance (ANOVA) was used to answer the second research question to determine whether significant differences existed in students' outcome gains between the two groups. The independent variable for the ANOVA was group membership (traditional or neuroscience education group) and the dependent variable was the mean scores on the post-assessment. All data were coded to protect the confidentiality of each student. The Statistical Package for the Social Sciences (SPSS) was employed to carry the statistical analyses with an 0.05 level of significance. ANOVA results in regard to the pre-assessment/post-assessment scores showed a significant difference in students' outcome gains (Table 2). Students pre-assessment mean scores indicated that the experimental and control group entered the course at a similar knowledge level. However, post-assessment revealed that the former was able to demonstrate a significantly outcome gain in relation to the control $(\mathrm{p}<0.05)$.

Table 2

Statistical Comparison of Students' Outcomes Gains

\begin{tabular}{lllll}
\hline Group & $\begin{array}{l}\text { Pre-test } \\
\text { mean }\end{array}$ & $\begin{array}{l}\text { Post-test } \\
\text { mean }\end{array}$ & F & Sig \\
\hline Traditional & 62.68 & 64.41 & 0.432 & $0.036^{*}$ \\
Neuroeducational & 60.85 & 69.20 & & \\
\hline
\end{tabular}

Note. $*$ Denotes significant difference at .05 level; df (degrees of freedom) $=40$.

\section{Recommendations for Further Study}

There are numerous possibilities for further study. The following are offered for consideration:

(1) Similar studies should be replicated with similar types of courses and larger sample sizes;

(2) The utilization of multiple methods of measuring learning outcomes can also be incorporated; and

(3) Long term impact in science learning.

\section{Conclusions}

Students showed positive comments about science, there was a noticeable increase in self-reported attitude toward science when laboratory classroom project was conducted. Large majority (above 60\%) reported that science was more enjoyable when activities and labs were part of the learning experience, they also felt that 
they learned better when they were in the science-lab classroom. Despite the small sample considered in this study, efficient implementation of neuroscience education, though experimental learning and higher-order cognitive skills in the classroom, resulted in a better post-assessment and higher degree of student engagement. This supports the application of neuroscience in the laboratory classroom in order to achieve a successful educational neuroscience approach in Science education.

\section{References}

Cross, P., \& Steadman, M. (1996). Classroom Research: Implementing the scholarship of teaching. San Francisco, CA: Jossey-Bass.

Hardiman, M. M. (2012). The Brain-Targeted Teaching Model for 21st-century schools. Thousand Oaks, CA: Corwin.

Sousa, D. (2009). How the Brain Influences Behavior: Management Strategies for Every Classroom. Thousand Oaks, CA: Corwin.

Sousa, D., \& Tomlinson, A. (2011). Differentiation and the Brain: How Neuroscience Supports the Learner-Friendly Classroom. Bloomington, IN: Solution Tree.

Whitman, G., \& Kelleher, I. (2016). Neuroteach: Brain science and the future of education. Maryland, USA; Rowman and Littlefield.

Wieman, C. (2008). Science Education. Collected Papers of Carl Wieman (pp. 661-663). World Scientific. 